\title{
Ruy Jornada Krebs: Vida e Obra de um Educador
}

\author{
Ruy Jornada Krebs: Life and Work of an Educator \\ Ruy Jornada Krebs: Vida y Obra de un Educador
}

\begin{abstract}
Fernando Copetti ${ }^{\mathrm{I}}$, Nadia Cristina Valentini ${ }^{\mathrm{II}}$, Maria Irany Knackfuss ${ }^{\mathrm{III}}$, Humberto Jefferson de Medeiros $^{\mathrm{IV}}$, Maria Helena da Silva Ramalho ${ }^{\mathrm{V}}$,
\end{abstract}

\begin{abstract}
Resumo
Este memorial tem como propósito narrar a vida e obra do Professor Ruy Jornada Krebs, um profissional dedicado ao estudo do desenvolvimento humano e ao ensino, à pesquisa e à extensão na Educação Física brasileira. O texto aborda a formação acadêmica, as primeiras atividades profissionais, a trajetória universitária do docente, sua história acadêmica no Centro de Educação Física e Desportos (CEFD) da Universidade Federal de Santa Maria (UFSM) e sua dedicação à Metodologia Globalizada e à Teoria Bioecológica do Desenvolvimento Humano. Também são consideradas para a discussão neste memorial a aposentadoria e a mudança para a Universidade do Estado de Santa Catarina (UDESC), bem como a continuidade produtiva na área. No ano em que o CEFD completa 50 anos, é realizada uma homenagem para um dos principais profissionais da Educação Física brasileira.
\end{abstract}

Palavras-chave: Educação Física; Esporte; Desenvolvimento Humano; Ecologia Humana; Educação

\begin{abstract}
This memorial aims to narrate the life and work of Professor Ruy Jornada Krebs, a professional dedicated to the study of human development and teaching, research and extension in Brazilian Physical Education. The text covers academic formative process, the first professional activities, the professor's university career, his academic history at Physical Education and Sports Center (CEFD) of Federal University of Santa Maria (UFSM) and his dedication to the Globalized Methodology and the Bioecological Theory of Human Development: Retirement and moving to State University of Santa Catarina (UDESC) are also considered for the discussion in this memorial, as well as the productive continuity in the area. In the year that CEFD celebrates 50 years, an honor is is given for one of the main Brazilian Physical Education professionals.
\end{abstract}

Keywords: Physical Education; Sport; Human Development; Human Ecology; Education

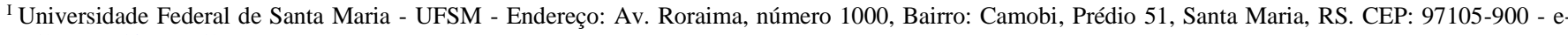
mail: copettif@gmail.com

II Universidade Federal do Rio Grande do Sul - UFRGS - e-mail: nadiacv@esef.ufrgs.br

III Universidade do Estado do Rio Grande do Norte - UERN - e-mail: kmariairany@ yahoo.com.br

III Universidade do Estado do Rio Grande do Norte - UERN - e-mail: hjmbeto@ gmail.com

${ }^{\text {III } U n i v e r s i d a d e ~ F e d e r a l ~ d e ~ J u i z ~ d e ~ F o r a ~-~ U F J R ~-~ e-m a i l: ~ m h e l e n a . r a m a l h o @ ~ g m a i l . c o m ~}$
} 


\section{Resumen}

Este memorial descriptivo tiene como objetivo contar la vida y el trabajo del profesor Ruy Jornada Krebs, un profesional dedicado a el desarrollo humano e y docencia, investigación y extensión de la Educación Física Brasileña. Formación académica, primeras actividades profesionales e ingreso y carrera universitaria. Se destaca su trayectoria académica en el Centro de Educação Física e Desportos (CEFD), en la Universidade Federal de Santa Maria (UFSM), y su dedicación a la Metodología Globalizada y a la Teoría Bioecológica del Desarrollo Humano. Como así también, su Jubilación y traslado a la Universidade do Estado de Santa Catarina (UDESC) y su productiva continuidad profesional. En el año en que CEFD celebra su 50 aniversario, se realiza el homenaje a uno de los principales profesionales de la Educación Física brasileña por sus contribuciones al CEFD.

Palabras clave: Educación Física; Deporte; Desarrollo humano; Ecologia humana; Educación

\section{Introdução}

Narrar a trajetória acadêmica do professor Ruy Jornada Krebs, um dos professores que contribuíram para o conhecimento e crescimento da área do desenvolvimento humano na Educação Física e para a consolidação do Centro de Educação Física e Desportos (CEFD) da Universidade Federal de Santa Maria (UFSM), é uma honra e um imenso desafio. Neste cinquentenário do CEFD apresentamos a trajetória desse Educador em sua essência, dedicado à vida acadêmica, na implementação de programas de pós-graduação, na pesquisa em desenvolvimento humano e na formação de profissionais com olhar bioecológico sobre o desenvolvimento e a aprendizagem. Com esse objetivo de retratar a colaboração deste profissional com a sociedade e preocupação na disseminação do conhecimento e formação profissional, traçamos uma trajetória temporal para apresentar as principais conquistas e transições de sua vida acadêmica.

Apresentamos uma breve contextualização da infância, a formação superior em Educação Física e sua qualificação na pós-graduação, o início de sua vida profissional na escola, ingresso no ensino superior e sua atuação no CEFD e UDESC. A formação de mestres e doutores, o estudo da criança e a fundação da Sociedade Internacional para Estudos da Criança (SIEC) são destacados, pois marcam a inserção e colaboração deste profissional para a saciedade. A alfabetização motora de crianças e sua metodologia globalizada recebem ênfase, pois foram bandeiras que carregou por toda sua vida. Destacamos também seu intensivo trabalho na introdução e disseminação da Teoria Bioecológica de Urie Bronfenbrenner no Brasil, em especial para a Educação Física e para o contexto do esporte no Brasil. As principais atividades acadêmicas e administrativas, com sua passagem pela administração central da universidade, a continuidade no ensino superior após a aposentadoria, e os prêmios e reconhecimentos por suas ações também são apresentados. 


\section{Ruy Jornada Krebs}

Ruy Jornada Krebs nasceu na cidade de Santiago, uma cidade do interior do estado do Rio Grande do Sul, chamada região missioneira, localizada próxima à fronteira com a Argentina, em 11 de julho do ano de 1948. Filho de Olgy Aquino Krebs e Clotilde Jornada Krebs. Foi o segundo de quatro irmãos, sendo Antônio Silvio Krebs o primogênito, e Vera Lúcia Krebs e Paulo Renato Krebs os irmãos mais novos.

Figura 1 - Ruy Jornada Krebs.

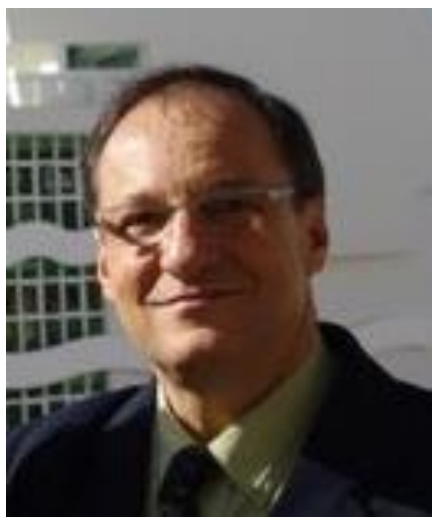

Fonte: Currículo Lattes do Prof. Ruy Jornada Krebs

Alguns relatos sobre sua infância estão descritos pela sua irmã no livro que homenageia os precursores do comportamento motor no Brasil. Os relatos retratam uma infância culturalmente rica, o gosto pela arte, música (costumava cantar trechos de ópera), literatura, arquitetura, e pelos esportes. A sua inteligência inquieta e muita simpatia marcam seus anos escolares. $\mathrm{O}$ desejo de harmonia e beleza, o anseio de liberdade e de expressão corporal plena foram determinantes para que escolhesse a formação em Educação Física. (VIEIRA et al., 2019). Aos 17 anos deixa Santiago rumo à capital Porto Alegre, em busca de sua formação no ensino superior.

Ruy inicia sua formação em 1967, na Escola Superior de Educação Física - ESEF, da Universidade Federal do Rio Grande do Sul. Durante a formação acadêmica, foi um aluno dedicado aos estudos, como relata seu colega de turma, professor Hélio Fuke ${ }^{1}$. Com a facilidade de aprender, que lhe era inerente, auxiliava os colegas fora dos horários de aula, principalmente nas disciplinas de Anatomia, Fisiologia, Cinesiologia e Biomecânica, as quais eram consideradas as mais difíceis do curso. O seu interesse pelos processos de formação e atuação profissional o levam a assumir a presidência do diretório

${ }^{1}$ Relato pessoal do professor Hélio Fuke, colega do professor Ruy Krebs durante o período da graduação na UFRGS e, posteriormente, colega docente no CEFD/UFSM. 
acadêmico do curso. Integrou a equipe da ESEF de voleibol, como levantador, e de tênis, para participar dos jogos gaúchos e brasileiros de estudantes de Educação Física. Formou-se no ano de 1969, com a nota média mais alta da turma.

Em 1976 ingressa no curso de especialização em Biomecânica no CEFD/UFSM. Nos anos de 1979 e 1980 se afasta do Brasil para cursar o Mestrado em Educação Física na University of Iowa, Estados Unidos, escrevendo a dissertação "Changes in Personality of Physical Education Students after Corporal Expression Practice". No ano de 1985, retorna aos Estados Unidos e inicia o curso de doutoramento na University of New Mexico, e, concomitante, um segundo mestrado. Em 1986 conclui o mestrado, com a dissertação "Project Future: Organized Sport For Children”, e, no ano seguinte, o doutorado, com a tese "Early Sport Specialization: a conceptual and causal-comparative study". Os trabalhos de dissertação e tese claramente evidenciam a preocupação com o desenvolvimento de crianças e jovens e marcam fortemente sua trajetória no estudo do desenvolvimento humano.

Os anos seguintes de sua trajetória acadêmica mostram um estudioso dedicado e apaixonado pelas teorias do desenvolvimento humano. Alguns anos depois, em 1994, com o intuito de estudar a teoria ecológica sobre o desenvolvimento humano de Urie Bronfenbrenner, afastou-se para o pós-doutorado na Indiana University, na área de desenvolvimento motor, tendo como supervisor o professor David Gallahue. Ao longo deste período, também estudou diferentes teorias do desenvolvimento, e este intenso período de formação se materializou posteriormente na publicação de dois livros, "Urie Bronfenbrenner e a ecologia do desenvolvimento humano" (KREBS, 1995a) e o "Desenvolvimento humano: Teorias e estudos" (KREBS, 1995b). A publicação desses dois livros repercute na área do desenvolvimento humano no Brasil norteando dissertações e teses, sendo adotados como referência, desde então, nos cursos de formação de graduação e pós-graduação.

\section{Professor de Educação Física e a carreira no ensino superior}

Com uma carreira marcada pela atuação no ensino superior, atuou brevemente como professor de Educação Física entre os anos de 1969 e1972 no Colégio Nossa Senhora dos Anjos, na região da Grande Porto Alegre; posteriormente, em Santa Maria, no Colégio Santa Maria e no Colégio Estadual Manoel Ribas (Maneco). Apaixonado pelo esporte, desde cedo, foi o responsável pela formação da primeira equipe feminina de Handebol do Colégio Maneco, passando em seguida a função de técnico ao professor 
Celso Giacomini. Como relata o professor Giacomini ${ }^{2}$, em uma excursão esportiva em que foram juntos, o Ruy criou uma música que contaminou a todos no ônibus, e que foi cantada durante toda a competição pelos alunos, demonstrando claramente a alegria de estar envolvido naquela atividade com seus alunos. Provavelmente essa preocupação em fazer do esporte algo prazeroso e saudável tenha sido um fator determinante para que sua formação de especialização e mestrado tenham tido como enfoque o esporte organizado para crianças.

A carreira na docência no ensino superior começou cedo. Foi convidado para ser professor das cadeiras de Handebol e Ginástica na Faculdade de Educação Física de Cruz Alta (FEFCA), onde atuou de em 1972 e 1973, deixando a instituição no ano de 1973, quando foi aprovado em concurso no CEFD/UFSM. Mesmo depois de assumir as atividades na UFSM, nunca deixou de atender aos convites para colaborar com a FEFCA, ministrando cursos e palestras (VIEIRA et al., 2019). Posteriormente, após sua aposentadoria na UFSM, passa a atuar na UDESC.

Ao longo de sua carreira, a amplitude de possibilidades e as demandas no ensino superior foram muitas. Embora tenha se envolvido em diversos afazeres administrativos, nunca deixou de se preocupar com o que acreditava ser a sua maior responsabilidade, ser um bom professor. Essa trajetória foi marcada pela forma como conduzia e assumia suas responsabilidades, conforme relata o professor Giacomini, seu colega e ex-diretor do CEFD. O professor Ruy "sempre se destacou por ser uma pessoa alegre, competente, que buscou transmitir os conteúdos das suas áreas de atuação com muita clarividência, com muita efetividade e claro, com competência, tanto que se tornou um dos professores mais queridos de todas as turmas com o qual ele trabalhou... e atuando de forma sempre a favorecer e a procurar o desenvolvimento do Centro".

A docência na graduação e pós-graduação, orientações de trabalhos de graduação, especialização, mestrado e doutorado, coordenação de projetos de pesquisa, iniciação científica, ensino e extensão pertenceram a sua rotina universitária. Para além dessas atividades que formam o tripé do "fazer universitário", as atividades administrativas de chefia, coordenação de curso, participação em comissões, representações, colegiados e conselhos, em todas essas, o Ruy teve efetiva participação nas instituições em que atuou, as quais de maior destaque são apresentadas.

\section{Formação de recursos humanos}

Ao longo dos 25 anos que trabalhou no CEFD ministrou disciplinas na graduação, inicialmente de Atletismo, Cinesiologia, Ginástica I, Ginástica II, Handebol, posteriormente se dedicando a Métodos e

\footnotetext{
${ }^{2}$ Relato pessoal do professor Celso Giacomini, colega do professor Ruy Krebs no Colégio Maneco e, posteriormente, colega docente no CEFD/UFSM.
} 
Técnicas de Ensino, Organização e Planejamento na Educação Física, e Desenvolvimento Humano, pela qual tinha especial carinho. No ensino de pós-graduação, ministrou as disciplinas de Currículo em Educação Física e Biomecânica para o curso de especialização. Com a criação dos cursos de mestrado e posteriormente de doutorado, dedicou-se às cadeiras de Metodologia da Pesquisa, Teorias do Desenvolvimento Humano, Pesquisa em Desenvolvimento Humano, Seminário em Dissertação e Desenvolvimento Motor.

Durante os anos iniciais na UFSM, o comprometimento na orientação de trabalhos de conclusão de curso de graduação, especialização, mestrado e doutorado já eram evidentes. No curso de especialização em Pesquisa e Ensino em Ciência do Movimento Humano orientou 13 monografias. No Programa de Pós-Graduação em Ciências do Movimento Humano orientou 27 dissertações de mestrado e 17 teses de doutorado, para além das co-orientações. As temáticas principais envolviam desenvolvimento físico, psicologia do esporte, pedagogia do esporte, e aprendizagem e desenvolvimento motor.

\section{Atividades administrativas}

A primeira atividade administrativa de destaque ocorre entre os anos de 1978 e 1981, quando o Ruy assume a coordenação do curso de Especialização em Técnicas Desportivas. Concomitantemente, entre 1978 e 1979 foi membro da equipe técnica do Núcleo de Assessoramento e Apoio Pedagógico do CEFD. Neste mesmo ano migra do Departamento de Educação Física para o Departamento de Métodos e Técnicas Desportivas, onde permanece até sua aposentadoria.

Em janeiro de 1981, após retornar de seu mestrado, ascende para a posição de professor Assistente. Nos anos seguintes, foi eleito coordenador do curso de Mestrado em Educação Física, atuando de 1982 a 1984. Ressalta-se que, em 1983 e 1984, o curso foi ranqueado pela Editora Abril como o melhor curso de mestrado na área no Brasil. Este período, e os anos que se sucederam, e com a criação do curso de doutorado, as demandas para orientar alunos de mestrado e doutorado crescem, e o Ruy passa a orientar estudantes das mais diversas partes do Brasil. Esses anos iniciais evidenciaram a formação de profissionais que passaram a atuar nas principais universidades brasileiras, os quais implementam seus próprios grupos de pesquisa, compartilhando seus ensinamentos e criando fortes laços acadêmicos. Isso produziu uma forte rede de colaboração no ensino e na pesquisa de dimensões nacionais, das quais muitas permanecem ainda ativas, mesmo após sua morte.

Administrativamente, ao retornar de seu doutorado no ano de 1987, assume, por quatro meses, como Pro Tempore a função de chefe do Departamento de Métodos e Técnicas Desportivas; e, é eleito na sequência para assumir por dois anos essa chefia. Retorna novamente a essa função por mais duas vezes, alguns anos depois, em 1992-1994, ao retornar das atividades de Pró-Reitor, e, em 1997, onde atuou por 
alguns meses até sua aposentadoria, neste mesmo ano. Destaca-se que, do ano de 1988 a 1990, foi o coordenador brasileiro do projeto Capes/Cofecub, convênio firmado entre a UFSM e Universitè BlaisePascal, França. Em 1989, participou como membro da comissão julgadora do VI prêmio MEC de literatura desportiva, assim como da comissão de reestruturação curricular do curso de Licenciatura em Educação Física do CEFD.

Ressalta-se que, entre os anos de 1989 e 1991, atuou como Pró-Reitor de Pós-Graduação e Pesquisa, um cargo de destaque que é conquistado por poucos profissionais na carreira universitária. Durante este período, além de todas as demandas inerentes à função de Pró-Reitor e conselhos que passa naturalmente a integrar, permaneceu com suas atividades didáticas e orientações. Manteve-se atuante nas representações e comissões no CEFD, como a comissão editorial do CEFD para incentivar a produção cientifica literária e editar a revista KINESIS; no conselho editorial da UFSM; no colegiado do curso de licenciatura; nas comissões de pesquisa e de extensão do CEFD; na comissão assessora da Biblioteca Central da UFSM; e como representante dos docentes do CEFD no Colegiado do Curso de Educação Especial do Centro de Educação. Em fevereiro de 1990 é aprovado em concurso público para a classe de professor Titular.

Após concluir suas atividades de Pró-Reitor de Pós-Graduação e Pesquisa, assume a chefia do departamento de Métodos e Técnicas Desportivas. Durante os anos de 1992 a 1994, participa da comissão assessora da Biblioteca Central da UFSM, e é nomeado Presidente Representante dos Cursos de PósGraduação do CEFD. Ao final deste período, se afasta para seu pós-doutorado nos Estados Unidos. Ao retornar, cria o Laboratório de Desenvolvimento Humano, que passa a integrar a estrutura do Laboratório de Pesquisa e Ensino do Movimento Humano - LAPEM, órgão suplementar setorial do CEFD. Foi nomeado para exercer a função de Diretor do LAPEM no final do ano de 1995.

\section{Colaboração com a sociedade}

A postura acadêmica e cidadã do Ruy foi marcada pela sua preocupação em retornar à sociedade todo o investimento que recebera, pois ressaltava que estudou em uma universidade pública e recebera bolsa para seus estudos de mestrado e doutorado. Preocupava-se em disseminar e compartilhar o conhecimento que havia aprendido. Quando convidado para ministrar seus cursos de capacitação, não se preocupava se receberia algum retorno financeiro por isso. Seu único pedido era que, se houvesse condições, pudesse levar gratuitamente seus alunos. Viajou por diversos municípios e estados no Brasil. Com uma motivação incansável e contagiante, compartilhou por anos sua proposta metodológica para o ensino da Educação Física. Essa energia e disposição intrínsecas a sua atuação, após o retorno de seu pósdoutorado, o conduzem para uma jornada dedicada também à organização de congressos para discutir, 
refletir, e propor estratégias para avançar no estudo e pesquisa sobre o desenvolvimento infantil, e para a necessidade de considerar uma abordagem bioecológica para o estudo do desenvolvimento humano.

Conta o professor Daniel Orey ${ }^{3}$, doutor em Educação Matemática, que foi seu colega durante o doutorado, que ao se reencontrarem no período do pós-doutorado, em 1994, conversavam sobre a ideia de criar um congresso ou seminário internacional voltado para o desenvolvimento das crianças. Tinham como base, fundamentar nas ideias de Bronfenbrenner e no trabalho multidisciplinar que ambos realizavam. Retornando ao Brasil, Ruy organizou o I Encontro para Estudos da Criança em Santa Maria, que sediou a reunião que constituiu a Sociedade Internacional para Estudos da Criança - SIEC, em agosto de 1995, da qual foi fundador e primeiro presidente. Estes eventos congregaram profissionais do Brasil, Europa, Estados Unidos e África do Sul, direcionados para profissionais e estudantes que, de alguma forma, congregavam seus esforços na promoção do desenvolvimento infantil, nos cuidados e nos direitos da criança e do adolescente.

Especial destaque merece o projeto de extensão em Equoterapia, que coordenou desde a sua criação em 1995, nascido de uma parceria entre a Brigada Militar e o Colégio Francisco Lisboa, incluiu acadêmicos e profissionais de várias áreas da UFSM, dedicado a pessoas com deficiência. Este foi o primeiro projeto de Equoterapia desenvolvido em uma Universidade Federal brasileira. Isso foi possível devido à vinda de profissionais da Associação Nacional de Equoterapia (ANDE-Brasil), no ano de 1994, com objetivo de difundi-la, bem como de capacitar professores e alunos para atuarem com essa prática terapêutica que utiliza o cavalo dentro de uma abordagem multidisciplinar e interdisciplinar, nas áreas de saúde, educação e equitação, buscando o desenvolvimento biopsicossocial de pessoas com deficiências e/ou necessidades especiais.

$\mathrm{Na}$ comunidade acadêmica da área do comportamento motor, manteve estreita relação com a Sociedade Brasileira de Comportamento Motor - SOCIBRACOM. Esta associação congrega profissionais e pesquisadores da área do Comportamento Motor em todo o território nacional, visando o apoio e aperfeiçoamento técnicos e científicos de profissionais e pesquisadores na área. Nesta associação foi presidente no período de 2006 a 2008. Na área da psicologia do esporte, foi membro do Managing Council da International Society of Sport Psychology, na gestão 2009 a 2012.

Ao longo de sua carreira recebeu inúmeros convites de universidades brasileiras e estrangeiras para colaborar, participando em bancas de mestrado, doutorado, ou processos públicos para seleção e promoção docente. Destacam-se suas participações na Universidade de São Paulo (USP), Universidade Estadual de Campinas (UNICAMP), Universidade Federal do Rio Grande do Sul (UFRGS), Universidade

\footnotetext{
${ }^{3}$ Relato pessoal do professor Daniel Orey, colega do professor Ruy Krebs durante o período de doutoramento. Posteriormente, foram membros fundadores da Sociedade Internacional para Estudos da Criança - SIEC.
} 
Federal de Minas Gerais (UFMG), Universidade do Estado de Santa Catarina (UDESC), Universidade Federal de Santa Catarina (UFSC), Universidade Federal do Rio Grande do Norte (UFRN), Universidade Federal do Rio de Janeiro (UFRJ), e Universidade Castelo Branco (RJ). Internacionalmente, também teve estreitos laços com a Universidade do Porto e com a Universidade Técnica de Lisboa, Portugal, bem como com a Universidade de Léon, Espanha.

\section{Prêmios e reconhecimentos}

No ano de 1984 recebeu um dos mais importantes prêmios da Educação Física, o Prêmio MEC de Literatura Esportiva Liselott Diem, MEC.

Durante o período que realizou seus estudos fora do Brasil, recebeu o Honnor Society Phy Kappa Phy, da Associação de Universidades Norte Americanas, e o The Wall of Honnor, University of New Mexico - Estados Unidos, ambos no ano de 1987.

Em sua terra natal, recebeu o título de Cidadão Santiaguense Ilustre, da Câmara Municipal de Santiago, RS, no ano de 1989.

Por sua atuação na área do comportamento motor, na qual foi um dos pioneiros da área no Brasil, recebeu o Prêmio Jefferson Canfield, da Sociedade Brasileira de Comportamento Motor, no ano de 2008.

Recebeu a distinção como um dos 10 Grandes Pensadores da Educação Física Brasileira, da Federação Internacional de Educação Física (FIEP), no ano de 2009.

\section{Produção acadêmica}

Sua primeira obra acadêmica foi o livro intitulado “A Educação Física que eles merecem”, no ano de 1983, que lhe rendeu o Prêmio Liselot Diem de literatura esportiva. Longos anos se passaram até que voltasse a se dedicar à produção de livros. Isso ocorreu ao retornar de seu pós-doutorado. Com o aprofundamento em teorias do desenvolvimento humano, inicia uma jornada destinada ao estudo dessas teorias e suas implicações para o desenvolvimento infantil, com dedicação e empenho ímpares para a Ecologia do Desenvolvimento Humano. Essa retomada iniciou com o livro "Urie Bronfenbrenner e a Ecologia do desenvolvimento humano" (KREBS, 1995a) e, com um grupo de seus alunos de pósgraduação e professores colaboradores organizou a obra "Desenvolvimento Humano: Teorias e estudos" (KREBS, 1995b), ambas de referência em cursos de graduação e pós-graduação. Com seus alunos de doutorado, escreveu também "Desenvolvimento Humano: uma área emergente da ciência do movimento 
humano" (KREBS et al., 1996), e "Teoria dos sistemas ecológicos: um paradigma para o desenvolvimento infantil”" (KREBS et al., 1997).

No ano de 1997, em colaboração com a psiquiatra e colega professora Fátima Deitos, junto com outros autores, organiza a obra "O diálogo corporal”, uma compilação de textos que tratavam temas ligados aos transtornos psicossomáticos e suas mais distintas relações com o corpo (DEITOS; KREBS; COPETTE, 1997). Organizou posteriormente uma sequência de obras em conjunto com diversos colaboradores atuantes na sociedade e que participavam dos Encontros para o Estudo da Criança, organizados pela SIEC. Foram elas: "Discutindo o desenvolvimento infantil” (KREBS; BELTRAME; COPETTI, 1998); "Perspectivas para o Desenvolvimento Infantil” (KREBS; COPETTI; BELTRAME; USTRA, 1999); "Desenvolvimento Infantil em Contexto" (KREBS; COPETTI; KRAEFF; SOUZA, 2001); e “Os Processos Desenvolvimentais na Infância” (KREBS; COPETTI; BELTRAME; PINTO, 2003). No ano de 2005, se dedica à obra "Educação Inclusiva e Necessidades Educacionais Especiais" (RODRIGUES; KREBS; FREITAS, 2005). Seu último livro foi "Tópicos em Desenvolvimento Motor na Infância e Adolescência” (KREBS; FERREIRA NETO, 2007).

Complementando esse conjunto de obras essenciais para a área do desenvolvimento infantil, publicou outros quatro livros que representaram a proposta metodológica que desenvolveu para a Educação Física Infantil (do ensino infantil ao ensino médio), conhecida como "Metodologia Globalizada", a qual disseminava em seus cursos. Essas obras foram elaboradas em cooperação com a Sociedade Educacional Positivo de Curitiba, no ano de 2001. Ao longo de sua carreira, colaborou também com 28 capítulos publicados de livros, sempre com foco no desenvolvimento da criança, com temas associados ao desenvolvimento motor e psicológico da criança, bem como o papel da Educação Física, da escola e da família nos processos do desenvolvimento infantil.

O primeiro registro de um artigo em revista científica data de 1977, elaborado durante seu curso de especialização em biomecânica, seguido de dez artigos nas duas décadas subsequentes. Foram os cinco últimos anos da carreira que lhe renderam o maior volume de produção de artigos, 38 artigos, pois sua dedicação anterior era para a produção de livros. Especial apreço teve por dois artigos que foi convidado a escrever para uma edição especial do International Journal of Sport Psychology, no ano 2009, onde nomes reconhecidos e atuantes da área das teorias ecológicas do desenvolvimento foram convidados para escrever sobre a abordagem ecológica no esporte e no exercício. O artigo uniu a teoria Bioecológica do Desenvolvimento Humano, com a temática que se dedicava a estudar, a criança no esporte, intitulado "Bronfenbrenner's Bioecological Theory of Human Development and the process of development of sports talent” (KREBS, 2009a), que mostrou, à luz da teoria, a complexa relação desse processo de formação do talento esportivo. O segundo artigo, "Proximal processes as the primary engines 
of development" (KREBS, 2009b), a convite do editor, aborda o elemento central da teoria de Bronfenbrenner de forma aplicada.

\section{Alfabetização motora e a Metodologia Globalizada}

O ensino da Educação Física, principalmente nas séries iniciais, sempre esteve no centro de suas preocupações e recebia especial atenção. Ruy ressaltava a necessidade de estimular as crianças desde cedo, alertando para a importância de uma alfabetização motora. No modelo de alfabetização proposto, estabelece uma analogia entre as experiências de movimento e de letramento das crianças. Enfatiza que as crianças no início do ensino fundamental deveriam estar alfabetizadas, tanto para as habilidades motoras fundamentais, quanto para a escrita e leitura. Defendia que, assim como a criança é ensinada sobre as letras, palavras, frases, sentenças e seus significados, deveria também o movimento ser ensinado. Desta forma, defendia que, sendo propiciado à criança experiência e oportunidades apropriadas de desenvolvimento com a mediação do professor, teria condições de redigir com propriedade e competência suas próprias práticas motoras. Para as crianças que manifestassem o desejo e as condições físicas e emocionais para se dedicarem ao desenvolvimento de novas habilidades, deveriam ser garantidas oportunidades adequadas de treinamento, para que a construção de careiras esportivas, de bailarinos e/ou outras de alta proficiência motora fossem observadas. Central a este processo, destacava a necessidade da intensidade pedagógica crescente que respeitasse a individualidade biológica da criança e seu tempo de aprendizado, evitando a especialização precocemente.

Ensinar Educação Física nas séries iniciais do ensino de primeiro grau é um desafio para muitos professores, e não foi diferente para o Ruy. Sempre considerou que cada criança é um indivíduo único e, simultaneamente, um indivíduo que tem muitas ou algumas características de seu grupo de convívio. Em suas considerações, reflexões e discussões ressaltava que os programas de Educação Física, que têm como centro os processos desenvolvimentistas, precisavam encontrar um equilíbrio entre as necessidades de cada criança e as necessidades de todas as crianças. Portanto, individualidade e sociabilidade são conceitos intrínsecos a sua proposta metodológica e que ajudam os professores a traçar as metas de cada programa.

Sua proposta da "Metodologia Globalizada" propunha, para as séries iniciais do ensino fundamental, as atividades de baixa organização, pré-desportivas, rítmicas, atividades de baixa complexidade e de autocontrole. Para as séries finais do ensino fundamental, elaborou fundamentos da aprendizagem coletiva, aprofundamentos da aprendizagem coletiva, fundamentos da aprendizagem individualizada, e aprofundamentos da aprendizagem individualizada. Para o planejamento do programa 
de Educação Física, sugeriu que os professores elaborassem um quadro curricular, que evidenciasse a sequência e o equilíbrio do programa para todas as séries. Neste deveria conter um plano anual, planos bimestrais, semanais para cada bimestre, e seus conteúdos diários específicos. Deveriam resumir no seu plano diário que decisões seriam suas e aquelas que seriam deixadas para as crianças. As cinco maiores áreas de atividades sugerem aos professores construir um ambiente educacional no qual as crianças tenham um papel ativo na construção do seu próprio entendimento da realidade. Ao longo dos anos, sua proposta de alfabetização motora e a Metodologia Globalizada permanecem atuais e têm instigado profissionais que atuam na área a implementá-las.

\section{A aposentadoria e a continuidade na carreira acadêmica}

O Ruy se aposentou após carreira dedicada ao CEFD/UFSM, em 11 de agosto de 1997, depois de ter atuado intensamente durante 25 anos na UFSM. Mesmo assumindo essa nova condição, continuou cooperando com o Programa de Pós-Graduação do CEFD/UFSM, na orientação de doutorandos e participando de bancas de defesa, e jamais deixou para trás seus laços acadêmicos e de amizade. Com a aposentadoria, inicia-se um novo ciclo, intensifica sua colaboração junto ao curso de Mestrado em Desenvolvimento Regional na Universidade de Santa Cruz do Sul - UNISC, onde permaneceu até o ano de 2000, orientando 09 dissertações de mestrado.

Paralelamente, desde o ano de 1998, assumiu como docente da Universidade do Estado de Santa Catarina - UDESC e mudou-se em definitivo para Florianópolis. Manteve sua característica de envolverse integralmente e atuar nas diversas esferas da Universidade. Ministrou as disciplinas de Psicologia do Esporte, Aprendizagem Motora, Currículo da Educação Física, nos cursos de Bacharelado e Licenciatura em Educação Física, onde orientou 81 trabalhos de conclusão de curso de graduação. No Programa de Pós-Graduação em Ciências do Movimento Humano do CEFID/UDESC, foi membro fundador e coordenador do Programa, ministrando as disciplinas de Psicologia do Desenvolvimento, Aprendizagem Motora, Docência Orientada, Seminário de Aprendizagem e Desenvolvimento Motor, orientando 25 dissertações de mestrado, de 2000 a 2010, deixando em andamento três orientações de mestrado e uma de doutorado.

Administrativamente, também deixou sua contribuição na Pró-Reitoria de Pesquisa e Desenvolvimento da UDESC, onde foi coordenador de Pesquisa e Pós-Graduação. Foi coordenador do Laboratório de Desenvolvimento e Aprendizagem Motora, fortalecendo os laços da UDESC com as 
Universidades do Porto e de Lisboa, organizando eventos nacionais e internacionais, destacando o Encontro dos Países de Língua Portuguesa.

Na extensão universitária, atuou no desenvolvimento e organização do projeto pedagógico e planejamento curricular para Educação Básica - Educação Física - da Rede Municipal de Ensino de São José, SC, de 1999 a 2010, resultando na publicação, em 2011, de um Caderno Pedagógico intitulado "Planejamento Curricular para Educação Básica - Educação Física" (KREBS; RAMALHO, 2011). Atuou neste período também como consultor da Rede Municipal de ensino de Florianópolis/SC, para a área de Educação Física.

Após seu falecimento, como lembrança da trajetória pessoal e profissional, foi homenageado pela UDESC - Itacurubi, com o descerramento da placa com seu nome, atribuída à Academia de Musculação.

\section{Considerações finais}

Ruy Krebs foi um educador pleno que atuou em todas as esferas que a carreira universitária pode permitir. Foi docente na graduação, pós-graduação, orientou trabalhos de conclusão de curso de graduação, especialização, mestrado e doutorado. Desenvolveu uma rede de relações com outros profissionais que permitiram uma formação diversificada de seus alunos. Coordenou projetos de pesquisa e extensão, participou de comissões, colegiados e conselhos, assumiu encargos de chefia e coordenação, bem como colaborou na administração central universitária. Foi reconhecido nacional e internacionalmente pelas suas contribuições para o ensino e pesquisa na Educação Física. Disseminou sua metodologia de ensino para a Educação Física na universidade e em redes públicas de ensino. Divulgou e aprofundou os estudos da Teoria Bioecológica do Desenvolvimento Humano para a Educação Física e o esporte no Brasil e no mundo.

Mensurar o alcance das suas contribuições é muito difícil. Nós, que convivemos por muitos anos com o professor Ruy, somos testemunhas de sua dedicação, competência e inovação no ensino e na pesquisa. Por onde passava, instigava profissionais a avançarem na produção do conhecimento e deixava laços duradouros de amizade. Não sabia dizer não a um pedido de ajuda ou colaboração. Sempre com seu sorriso e otimismo contagiantes, cativava as pessoas. Sempre tinha uma novidade boa para contar! As ruins, quase sempre, guardava para si. Dez anos se passaram desde sua precoce partida, mas seu legado acadêmico e as díades primárias que estabeleceu permanecem, e ainda se multiplicam. 


\section{Referências}

DEITOS, Fátima; KREBS, Ruy J.; COPETTE, Fábio R. (Orgs.) Diálogo corporal. Santa Maria: Casa do Zé, 1997.

KREBS, Ruy J. Urie Bronfenbrenner e a ecologia do desenvolvimento humano. 1. ed. Santa Maria: Casa Editorial, 1995a.

KREBS, Ruy J. Desenvolvimento humano: Teorias e estudos. Santa Maria: Casa Editorial, 1995b.

KREBS, Ruy J. et al. Desenvolvimento humano: Uma área emergente da ciência do movimento humano. Santa Cruz do Sul, 1996.

KREBS, Ruy J. et al. Teoria dos Sistemas Ecológicos: Um paradigma para o desenvolvimento infantil. Universidade Federal de Santa Maria, 1997.

KREBS, Ruy J.; BELTRAME, Thaís; COPETTI, Fernando. Discutindo o desenvolvimento infantil. Santa Maria: Pallotti, 1998.

KREBS, Ruy J. et al. (Org.). Perspectivas para o desenvolvimento infantil. Santa Maria: SIEC, 1999.

KREBS, Ruy J. et al. (Org.). Desenvolvimento infantil em contexto. Florianópolis: Editora da UDESC, 2001.

KREBS, Ruy J. et al. (Org.). Os processos desenvolvimentais na infância. Belém: GTR Gráfica e Editora Ltda., 2003.

KREBS, Ruy J.; FERREIRA NETO, Carlos A. Tópicos em desenvolvimento motor na infância e adolescência. Rio de Janeiro: LECSU, 2007.

KREBS, Ruy J. Bronfenbrenner's Bioecological Theory of Human Development and the process of development of sports talent. International Journal of Sport Psychology, v.40, p.108-135, 2009a. Disponível em: http://www.ijsp-online.com/abstract/view/40/108 Acesso em: 20 de jun. 2020.

KREBS, Ruy J. Proximal processes as the primary engines of development. International Journal of Sport Psychology, v.40, p.219-228, 2009b. Disponível em: http://www.ijsponline.com/abstract/view/40/219 Acesso em: 20 de jun. 2020.

KREBS, Ruy J.; RAMALHO, Maria Helena S. (Orgs.). Planejamento curricular para educação básica: Educação Física - Caderno Pedagógico. Florianópolis: IOESC, 2011.

RODRIGUES, Davi; KREBS, Ruy J; FREITAS, Soraia. Educação inclusiva e necessidades educacionais especiais. Santa Maria: Editora da Universidade Federal de Santa Maria, 2005.

VIEIRA, José Luís L. et al. Ruy Jornada Krebs: Um dos pilares da Educação Física brasileira. In: MORAES, Renato; RODRIGUES, Sérgio Tosi (Orgs.). Os pesquisadores pioneiros em comportamento motor no Brasil. 1.ed., v.01, Bauru - SP: Canal6 Editora, 2018. p.57-70. 


\section{Agradecimentos}

Aos colegas do professor Ruy, que contribuíram com seus relatos para este memorial, professores Daniel Orey, Luiz Celso Giacomini e Hélio Fuke.

\section{Como citar este artigo}

COPETTI, F.; VALENTINI, N. C.; KNACKFUSS, M. I.; MEDEIROS, H. J.; RAMALHO, M . H. S. Ruy Jornada Krebs: Vida e Obra de um Educador. Revista Kinesis, Santa Maria, Dossiê CEFD 50 anos, p.01-15, 2020.

* O presente trabalho não contou com apoio financeiro de nenhuma natureza para sua realização. 